\title{
Myeloid Neoplasms with Germline GATA2 Mutation
}

National Cancer Institute

\section{Source}

National Cancer Institute. Myeloid Neoplasms with Germline GATA2 Mutation. NCI

Thesaurus. Code C151912.

Myelodysplastic syndromes/acute myeloid leukemias associated with germline GATA2

mutation. 